\title{
Lifetime prevalence of suicidal ideation among men who have sex with men: a meta-analysis
}

\author{
Zhenzhou Luo ${ }^{1,2} \mathbb{D}$, Tiejian Feng ${ }^{3}$, Hanlin $\mathrm{Fu}^{1}$ and Tubao Yang ${ }^{1 *}$
}

\begin{abstract}
Background: Suicide is a leading cause of death among men who have sex with men (MSM) and suicidal ideation may put individuals at higher risk of suicide. A great disparity of lifetime prevalence of suicidal ideation among MSM was observed across studies, indicating the importance of a reliable estimation of the pooled lifetime prevalence. However, the only one published meta-analysis estimating the pooled lifetime prevalence of suicidal ideation among MSM was conducted in 2008 with only 2 eligible studies. Subsequently, there was a rapid increase of publications about lifetime suicidal ideation among MSM, suggesting that an update on the pooled lifetime prevalence of suicidal ideation among MSM was necessary. Therefore, this study aimed to update the estimation of the pooled lifetime prevalence of suicidal ideation among MSM.

Methods: Electronic databases of PubMed, CINAHL, Scopus (social science), Embase and Psyclnfo were searched until September 2017 to identify relevant studies. Cross-sectional studies exploring the lifetime prevalence of suicidal ideation among MSM were enrolled. Heterogeneity was evaluated using the Cochran $Q$ test and quantified using the $P$ statistic. The possibility of publication bias was assessed using both Begg's rank test and Egger's linear test, and an Egger's funnel plot for asymmetry was presented. Subgroup analyses were performed according to the geographic area, sample source and HIV status.
\end{abstract}

Results: Nineteen studies with a total of 26,667 MSM were included, of which 9374 were identified with suicidal ideation. A high degree of heterogeneity $\left(P \leq 0.001, P^{2}=99.2 \%\right)$ was observed among the eligible studies, with the reported prevalence ranging from 13.18 to $55.80 \%$. The pooled lifetime prevalence of suicidal ideation among MSM by a random effects model was 34.97\% (95\% confidence interval: 28.35\%-41.90\%). Both the Begg's rank test and Egger's linear test indicated low possibility of publication bias. Subgroup analyses showed that the lifetime prevalence of suicidal ideation among MSM differed significantly by geographic area, sample source and HIV status $(P<0.05)$.

Conclusions: The high pooled lifetime prevalence of suicidal ideation among MSM found in this meta-analysis significantly underscores the importance of early assessment of suicidal ideation among MSM, as well as the need for strengthening the psychological interventions.

Keywords: Suicidal ideation, Men who have sex with men, Prevalence, Meta-analysis

\footnotetext{
* Correspondence: 1064960669@qq.com

'Department of Epidemiology and Health Statistics, Xiangya School of Public

Health, Central South University, Hunan, China

Full list of author information is available at the end of the article
} 


\section{Background}

Suicide, a leading cause of death among men who have sex with men (MSM), has become a public health issue [1]. In Canada, more MSM are estimated to have died from suicide than from HIV-related illness in 2011 [1], and in China, a rapid increase of suicide-related behaviors among MSM has been frequently reported [2-4]. Suicidal ideation, defined as thinking about, considering or planning for suicide [5], may lead to higher risk of suicide $[6,7]$. In a review by David Klonsky et al., it has been suggested that an important reason for the limited achievement in reducing suicide is inadequate knowledge, especially about why and when suicidal ideation progresses to potentially suicidal attempts [6]. Additionally, the risk for suicide is significantly higher in those with suicidal ideation than those without suicidal ideation [7]. Furthermore, compared with heterosexual males, MSM are at higher risk for suicidal ideation $[8,9]$, which may be associated with the discrimination and stigma brought by their sexual orientation $[8,10,11]$. For example, in a worldwide population-based study, Mathy found that MSM in South America, North America and Asia were at 7.5, 2.1 and 2.9 times higher risk for suicidal ideation than heterosexual males, respectively [12]. Based on these findings, the assessment of suicidal ideation is imperative among MSM.

Numerous studies have estimated the lifetime prevalence of suicidal ideation among MSM. However, the reported prevalence varied greatly across studies, ranging from 10.6 to $55.3 \%[13,14]$, indicating the importance of a reliable estimation of the pooled lifetime prevalence of suicidal ideation among MSM, which could help the service providers to identify the accurate amount of those with suicidal ideation and hence implement appropriate interventions to reduce suicide. Literature search showed that there was one published meta-analysis which estimated the pooled lifetime prevalence of suicidal ideation among MSM [15]. However, the meta-analysis included exclusively studies with a concurrent heterosexual comparison group, and only 2 studies were included when estimating the pooled lifetime prevalence, which significantly lowered the generalizability of their findings. Furthermore, the metaanalysis was conducted in 2008 and, subsequently, there was a rapid increase of publications about lifetime suicidal ideation among MSM, suggesting that an update on the pooled lifetime prevalence of suicidal ideation among MSM was necessary. Therefore, this study aimed to update the estimation of the pooled lifetime prevalence of suicidal ideation among MSM.

In addition, previous studies have indicated that suicide-related behaviors among sexual minorities differed with different sample sources and HIV statuses $[11,16]$. For example, in a study by Hottes et al., it was found that the pooled lifetime prevalence of suicidal attempt in lesbian, gay and bisexual (LGB) individuals for population-based and community-based surveys was 11 and 20\%, respectively [16], and HIV-positive MSM were at higher risk of suicidal ideation than HIVnegative MSM [11]. Also, the prevalence of suicidal ideation among MSM may differ by geographic area, which could be explained by the differences in sociodemographic factors and economical levels, as well as the cross-cultural differences in the attitude towards sexual minorities [12]. For example, it has been estimated that the lifetime prevalence of suicidal ideation among MSM in North America and South America was 22.6 and $34.6 \%$, respectively [12]. Therefore, the pooled lifetime prevalence stratified by geographic area, sample source and HIV status was also explored in this study.

\section{Methods}

\section{Search strategy}

This meta-analysis was based on the Preferred Reporting Items for Systematic Reviews and Meta-Analyses (PRISMA) guidelines (the Additional file 1). Electronic databases of PubMed, CINAHL, Scopus (social science), Embase and PsycInfo were searched until September 2017. Subject headings were used where possible; otherwise text words were used. Consistent with previous meta-analyses on the MSM population [17-19], MSM were identified by using a broad set of text words in this meta-analysis, including MSM, men who have sex with men, homosexual, homosexuality, bisexual, bisexuality and gay. Specifically, for the databases of Embase and PsycInfo, a combination of the subject headings "suicidal ideation" and "male homosexuality" was used, while for the databases of PubMed, CINAHL and Scopus, the search terms were "((lifetime[Text Word]) AND suicid"[Text Word] $)$ AND (((()(homosexuality[Text Word]) OR bisexuality[Text Word]) OR gay[Text Word]) OR bisexual[Text Word]) OR MSM[Text Word]) OR men who have sex with men[Text Word]) OR homosexual[Text Word])". The reference lists of four reviews about suiciderelated behaviors in sexual minorities $[15,16,20,21]$ and all included studies were hand searched for further relevant articles.

\section{Eligibility criteria}

Articles were included in this meta-analysis if they fulfilled the following criteria: (1) the study design of the article was cross-sectional; (2) the target population of the article focused on or included men who have had sexual intercourse with men, and/or men who have been sexually attracted to men $[22,23]$; (3) the article employed a clear definition of suicidal ideation with a binary response of "yes" or "no"; (4) the article provided information on the sample size and lifetime prevalence 
of suicidal ideation; (5) the article was published in a peer-reviewed journal in English language. Articles were excluded if: (1) they specifically targeted only participants who sought mental health services; (2) they specifically targeted only youths or adolescents, though age was not a restriction in this meta-analysis; (3) they were review, book chapter, case-report or comment. Additionally, if repeated data were observed between different articles, only the earlier publication was included.

\section{Data extraction}

Two investigators extracted relevant data independently and carefully, and any inconsistencies between them were further discussed and resolved by consensus. The outcome of this meta-analysis was the lifetime prevalence of suicidal ideation. Though suicidal attempt is considered better proxies for suicide death than suicidal ideation [16], knowledge about why and when suicidal ideation progresses to suicidal attempts remains inadequate, indicating the importance of the estimation of lifetime prevalence of suicidal ideation.

For all included studies, the following data were extracted: first author, year of publication, location of study, sample source, sampling method, number of participants with suicidal ideation, sample size, and quality of study. Additionally, if available, data on geographic area and HIV status were also extracted. Consistent with previous meta-analyses, the geographic area was categorized into high-income countries, and low- and middleincome countries, and the sample source was categorized into population-based and community-based [16, 24]. Specifically, population-based surveys involved predominantly heterosexual individuals and community-based surveys involved exclusively MSM from the venues that MSM visits (e.g., gay bars, clubs, and MSM Web sites).

\section{Quality assessment}

Consistent with previous meta-analyses on cross-sectional studies, the Agency for Healthcare Research and Quality (AHRQ) was used to assess the quality of eligible articles $[25,26]$. It is an 11-item scale with Yes/No/Unclear response options. This scale focuses on assessing the quality of reporting, with most of the items assessing whether or not relevant information was reported. The response of "Yes" for each item was scored "1", and the response of "No" or "Unclear" for each item was scored "0". A total score of 0 to 3,4 to 7 , and 8 to 11 indicates low, moderate, and high quality, respectively.

\section{Statistical analysis}

All statistical analyses for this study were performed using the statistical software $\mathrm{R}$ version 3.4.1. Heterogeneity was assessed using the Cochran $Q$ test and quantified using the $I^{2}$ statistic. The pooled lifetime prevalence of suicidal ideation among MSM was estimated using FreemanTukey transformation of inverse hyperbolic sine function method by a random effects model when significant heterogeneity $\left(P \leq 0.10, I^{2}>50 \%\right)$ was observed. Otherwise, a fixed effects model was used [27]. Sensitivity was assessed by the effect of excluding articles with low quality on the stability of the pooled prevalence [28, 29]. Publication bias was evaluated using both Begg's rank test and Egger's linear test, and an Egger's funnel plot for asymmetry was presented [30, 31]. Subgroup analyses were performed according to the geographic area, sample source and HIV status. The $\chi^{2}$ test was used to assess the difference across subgroups [28, 32, 33] and the significant level was set at $P<0.05$.

\section{Results}

\section{Search results}

A total of 774 articles were initially yielded for this meta-analysis. Of these, 53 full articles were shortlisted for the eligibility assessment. Among the 53 articles, 25 were excluded for not reporting the lifetime prevalence of suicidal ideation among MSM, 3 were excluded for not employing a clear definition of suicidal ideation, 2 were excluded for repeated data, and 4 were excluded for targeting only youths or adolescents or only participants who sought mental health services. Finally, 19 articles were included in this meta-analysis (Fig. 1).

\section{Study characteristics}

The characteristics of eligible studies are presented in Table 1. A total of 26,667 participants were involved, of which 9374 were identified with lifetime suicidal ideation. Among the 19 eligible studies, 11 were conducted in high-income countries (including USA, Canada, United Kingdom, Netherlands, Switzerland, and Estonia) and 7 were conducted in low- and middle- income countries (including Lao People's Democratic Republic, Nepal, China, Uganda, Gambia, Togo, and Burkina Faso); 6 were population-based surveys and 13 were community-based surveys; 7 used random sampling method and 7 used snowball sampling method and/or respondent-driving sampling method; furthermore, according to the AHRQ scale, 17 were identified with moderate quality, and 2 were identified with low quality (the Additional file 2).

\section{Pooled lifetime prevalence of suicidal ideation among MSM}

The lifetime prevalence of suicidal ideation reported in eligible studies ranged from $13.18 \%$ [10] to $55.80 \%$ [34], with the lowest reported in three West African countries (including Gambia, Togo and Burkina Faso) and the highest in Switzerland. Significant heterogeneity $(P \leq$ $0.001, I^{2}=99.2 \%$ ) was observed among the eligible 


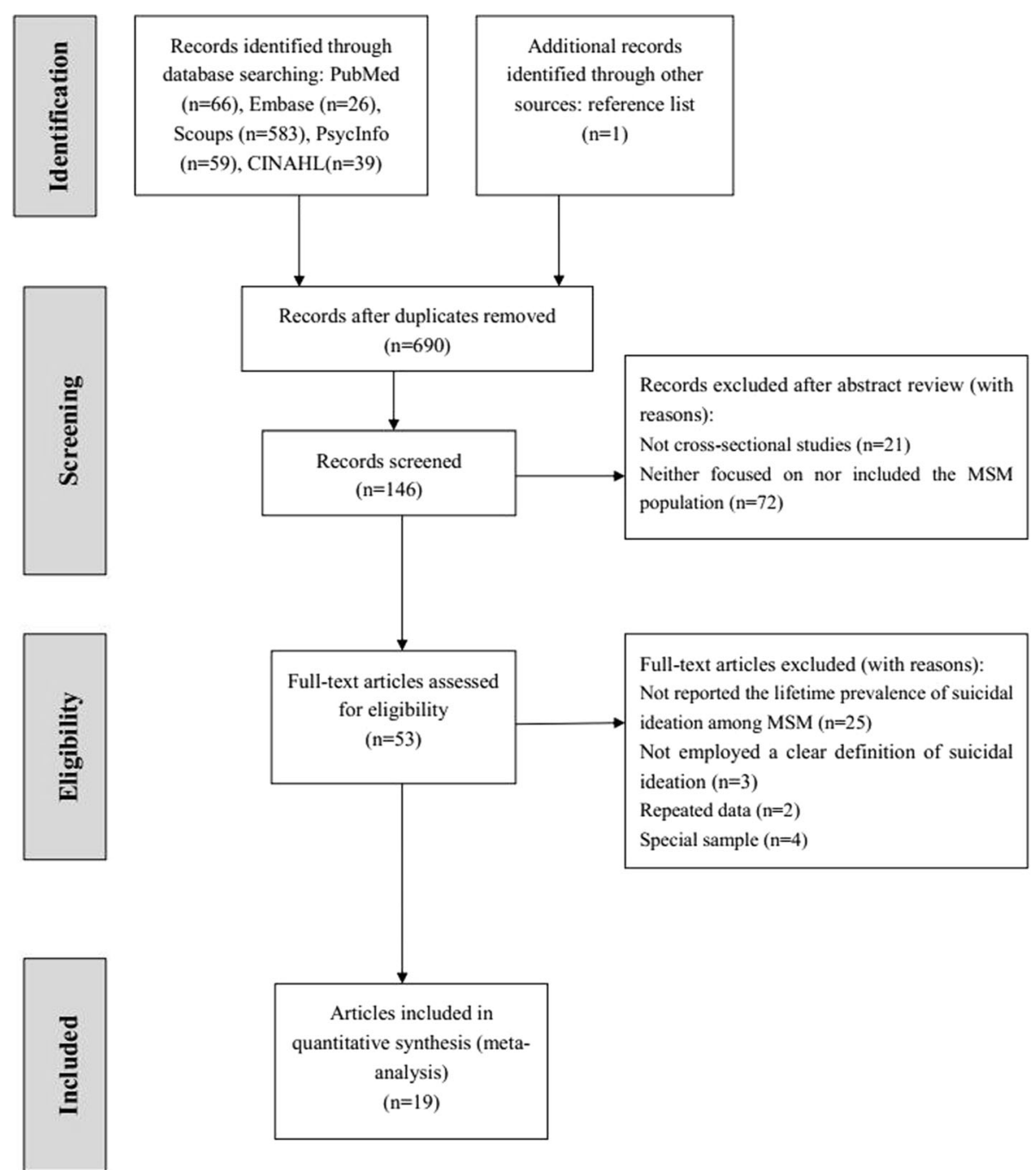

Fig. 1 Flow chart of study identification and selection

studies and a random effects model was used to estimate the pooled lifetime prevalence. The pooled lifetime prevalence of suicidal ideation among MSM was 34.97\% (95\% confidence interval (CI): 28.35\%-41.90\%). Figure 2 shows the details.

\section{Sensitivity analysis and publication bias}

After excluding 2 articles with low quality, the pooled lifetime prevalence of suicidal ideation decreased slightly from $34.97 \%$ (95\% CI: $28.53 \%-41.90 \%$ ) to $34.61 \%$ (95\% CI: $28.67 \%-40.79 \%)$, suggesting low sensitivity of this meta-analysis.

In addition, both the results of Begg's rank test $(\mathrm{z}=1.434$, $P=0.152)$ and Egger's linear test $(t=-0.392, P=0.700)$ indicated low possibility of publication bias. Consistent with Egger's linear test, the Egger's funnel plot was symmetrical (Fig. 3).

\section{Subgroup analyses}

The results of subgroup analyses are shown in Table 2 . The pooled lifetime prevalence of suicidal ideation in high-income countries, and low- and middle- income countries was $42.55 \%$ (95\% CI: $34.78 \%-50.50 \%)$ and $25.78 \%$ (95\% CI: $17.33 \%-35.26 \%$ ), respectively. The pooled lifetime prevalence in population-based and community-based surveys was $30.58 \%$ (95\% CI: $26.25 \%-$ $35.09 \%)$ and $36.34 \%$ (95\% CI: $26.93 \%-46.32 \%)$, respectively. The pooled lifetime prevalence among HIVpositive and HIV-negative MSM was $25.75 \%$ (95\% CI: $17.64 \%-34.76 \%$ ) and $16.99 \%$ (95\% CI: $3.17 \%-38.52 \%$ ), respectively. Besides, the heterogeneity was high in most subgroups. However, the heterogeneity was quite low when estimating the pooled lifetime prevalence of suicidal ideation in HIV-positive MSM $\left(P=0.269, I^{2}=18.0\right)$.

Subgroup analyses also indicated that the lifetime prevalence of suicidal ideation among MSM differed 
Table 1 Characteristics of the studies included in this meta-analysis

\begin{tabular}{|c|c|c|c|c|c|c|c|}
\hline First author & $\begin{array}{l}\text { Year of } \\
\text { publication }\end{array}$ & Location of study & $\begin{array}{l}\text { Sample } \\
\text { source }\end{array}$ & Sampling method & $\begin{array}{l}\text { Number of MSM with } \\
\text { suicidal ideation }\end{array}$ & $\begin{array}{l}\text { Sample } \\
\text { size }\end{array}$ & $\begin{array}{l}\text { Quality of } \\
\text { study }\end{array}$ \\
\hline Cochran [49] & 2000 & USA & $\begin{array}{l}\text { Population- } \\
\text { based }\end{array}$ & Random sampling & 32 & 78 & Moderate \\
\hline Mathy [12] & 2002 & Worldwide & $\begin{array}{l}\text { Population- } \\
\text { based }\end{array}$ & Internet & 878 & 3887 & Moderate \\
\hline Botnick [50] & 2002 & Canada & $\begin{array}{l}\text { Community- } \\
\text { based }\end{array}$ & Not reported & 150 & 345 & Moderate \\
\hline Warner [51] & 2004 & United Kingdom & $\begin{array}{l}\text { Community- } \\
\text { based }\end{array}$ & Snowball sampling & 357 & 741 & Moderate \\
\hline de Graaf [8] & 2006 & Netherlands & $\begin{array}{l}\text { Population- } \\
\text { based }\end{array}$ & Random sampling & 33 & 82 & Moderate \\
\hline Sheridan [52] & 2009 & $\begin{array}{l}\text { Lao People's } \\
\text { Democratic Republic }\end{array}$ & $\begin{array}{l}\text { Community- } \\
\text { based }\end{array}$ & Venue-day-time sampling & 90 & 540 & Moderate \\
\hline Brennan [53] & 2010 & Canada & $\begin{array}{l}\text { Population- } \\
\text { based }\end{array}$ & Random sampling & 268 & 948 & Moderate \\
\hline Wang [14] & 2012 & Switzerland & $\begin{array}{l}\text { Community- } \\
\text { based }\end{array}$ & Random sampling & 316 & 571 & Moderate \\
\hline Deuba [54] & 2013 & Nepal & $\begin{array}{l}\text { Community- } \\
\text { based }\end{array}$ & Snowball sampling & 159 & 339 & Moderate \\
\hline Wang [34] & 2013 & Switzerland & $\begin{array}{l}\text { Community- } \\
\text { based }\end{array}$ & Random sampling & 154 & 276 & Moderate \\
\hline Chen [55] & 2015 & China & $\begin{array}{l}\text { Community- } \\
\text { based }\end{array}$ & Snowball sampling & 398 & 1530 & Low \\
\hline Ferlatte [56] & 2015 & Canada & $\begin{array}{l}\text { Community- } \\
\text { based }\end{array}$ & Internet & 4180 & 8382 & Low \\
\hline Parker [57] & 2015 & Estonia & $\begin{array}{l}\text { Community- } \\
\text { based }\end{array}$ & Internet & 118 & 265 & Moderate \\
\hline Blosnich [58] & 2016 & USA & $\begin{array}{l}\text { Population- } \\
\text { based }\end{array}$ & Random sampling & 269 & 756 & Moderate \\
\hline Hottes [59] & 2016 & Canada & $\begin{array}{l}\text { Population- } \\
\text { based }\end{array}$ & Random sampling & 1289 & 4675 & Moderate \\
\hline $\mathrm{Mu}[47]$ & 2016 & China & $\begin{array}{l}\text { Community- } \\
\text { based }\end{array}$ & Respondent-driven sampling & 148 & 807 & Moderate \\
\hline Hladik [60] & 2016 & Uganda & $\begin{array}{l}\text { Community- } \\
\text { based }\end{array}$ & Respondent-driven sampling & 270 & 608 & Moderate \\
\hline Stahlman [10] & 2016 & $\begin{array}{l}\text { Gambia, Togo, Burkina } \\
\text { Faso }\end{array}$ & $\begin{array}{l}\text { Community- } \\
\text { based }\end{array}$ & $\begin{array}{l}\text { Respondent-driven sampling and } \\
\text { snowball sampling }\end{array}$ & 205 & 1555 & Moderate \\
\hline Kohlbrenner [61] & 2016 & Nepal & $\begin{array}{l}\text { Community- } \\
\text { based }\end{array}$ & Respondent-driven sampling & 60 & 282 & Moderate \\
\hline
\end{tabular}

significantly by geographic area, sample source and HIV status $(P<0.05)$. Specifically, the lifetime prevalence of suicidal ideation was significantly higher in high-income countries (vs. low- and middle- income countries), in community-based surveys (vs. population-based surveys) and in HIV-positive MSM (vs. HIV-negative MSM).

\section{Discussion}

This meta-analysis provided an update on the pooled lifetime prevalence of suicidal ideation among MSM. Nineteen eligible studies with a total of 26,667 participants were involved, of which 9374 were identified with suicidal ideation. The reported lifetime prevalence of suicidal ideation ranged from $13.18 \%$ [10] to $55.80 \%$ [34] among the eligible studies, and the pooled lifetime prevalence of suicidal ideation among MSM by a random effects model was $34.97 \%$ (95\% CI: $28.35 \%-$ $41.90 \%)$.

The pooled lifetime prevalence of suicidal ideation among MSM found in this study (34.97\%) was not only much higher than that among general population found in previous meta-analyses (3.9-11.5\%) [35-38], but also higher than the lifetime prevalence of suicidal ideation among lesbians found in some previous studies. For example, in a general population-based sample from the Netherlands, de Graaf et al. found that the lifetime 


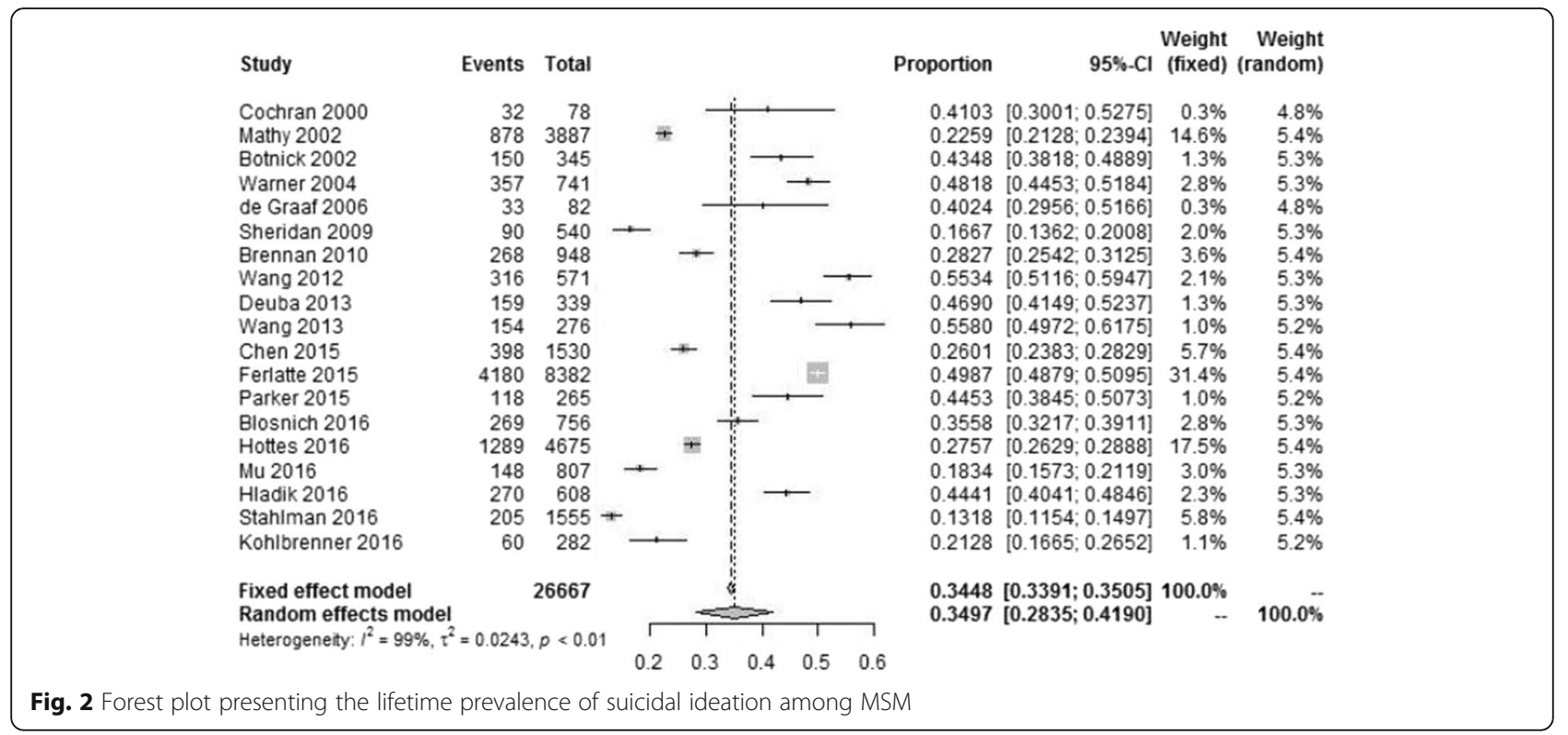

prevalence of suicidal ideation among lesbians was 23.3\% [8], and in a Canadian population-based study by Steele et al., this rate was $29.5 \%$ [39]. The high pooled lifetime prevalence of suicidal ideation among MSM found in this study, which may be associated with the discrimination, stigma, prejudice and isolation brought by their sexual orientation $[8,10,11]$, significantly underscores the importance of early assessment of suicidal ideation among MSM, as well as the need for strengthening the psychological interventions.

Subgroup analysis found that the lifetime prevalence of suicidal ideation in high-income countries was higher than that found in low- and middle- income countries. This tendency was contradictory to a study by Mathy, which showed that the lifetime prevalence of suicidal ideation among MSM was $22.6 \%$ in North America and $34.6 \%$ in South America [12]. The high heterogeneity

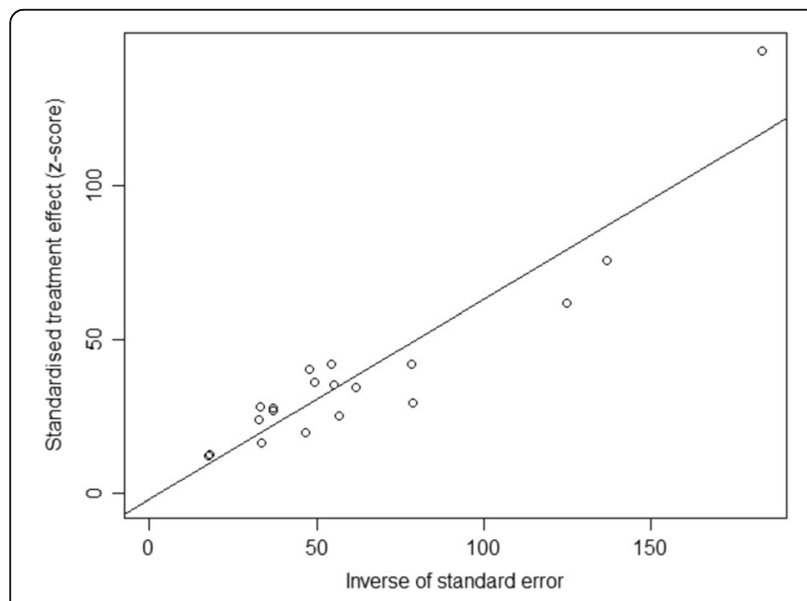

Fig. 3 Egger's funnel plot of the 19 included studies in this meta-analysis observed when estimating the pooled lifetime prevalence stratified by geographic area $\left(I^{2}=98.8 \%\right.$ for studies involved in high-income countries and $I^{2}=98.3 \%$ for studies involved in low- and middle- income countries) may lead to the contradictory results. More cross-cultural studies are warranted to better clarify the difference in the lifetime prevalence of suicidal ideation observed in different geographic areas.

Subgroup analyses also indicated that the lifetime prevalence of suicidal ideation differed significantly between different sample sources. Specifically, MSM from community-based surveys exhibited higher lifetime prevalence of suicidal ideation, in comparison with those from population-based surveys. This finding is consistent with a previous meta-analysis [16]. By pooling 30 cross-sectional studies conducted in North America and Western Europe, Hottes et al. found that the pooled lifetime prevalence of suicidal attempt was 11 and 20\% among LGB individuals from population-based and community-based surveys, respectively [16]. Venuebased LGB community surveys may induce selection bias and tended to overrepresent gay or lesbianidentified, urban, and high-income sexual minorities [40], thus contributing to a higher lifetime prevalence of suicide-related behaviors.

Additionally, this meta-analysis found that the lifetime prevalence of suicidal ideation among HIV-positive MSM was much higher than that among HIV-negative MSM, indicating more attention should be paid to HIV-positive MSM. Suicidal ideation may arise as the infected MSM learned of their HIV status [41]. This was mainly due to the fact that compared with HIV-negative MSM, HIVpositive MSM may experience higher levels of stigma associated with increased risk for suicidal ideation [11]. 
Table 2 Subgroup analyses of the lifetime prevalence of suicidal ideation among MSM

\begin{tabular}{|c|c|c|c|c|c|c|c|c|c|}
\hline \multirow[t]{3}{*}{ Subgroup } & & \multirow{3}{*}{$\begin{array}{l}\text { Number. } \\
\text { of } \\
\text { studies }\end{array}$} & \multirow{3}{*}{$\begin{array}{l}\text { MSM } \\
\text { with } \\
\text { suicidal } \\
\text { ideation }\end{array}$} & \multirow{3}{*}{$\begin{array}{l}\text { Total } \\
\text { sample }\end{array}$} & \multirow{3}{*}{$\begin{array}{l}\text { Pooled prevalence } \\
\text { of suicidal ideation } \\
(95 \% \mathrm{Cl})(\%)\end{array}$} & \multirow{2}{*}{\multicolumn{2}{|c|}{ Heterogeneity }} & \multirow{2}{*}{\multicolumn{2}{|c|}{ Between group difference }} \\
\hline & & & & & & & & & \\
\hline & & & & & & & & & \\
\hline \multirow[t]{3}{*}{ Geographic area } & & & & & & & & 613.596 & $<0.001$ \\
\hline & High-income countries & 11 & 7166 & 17,119 & $42.55(34.78-50.50)$ & 98.8 & $<0.001$ & & \\
\hline & $\begin{array}{l}\text { Low- and middle- income } \\
\text { countries }\end{array}$ & 7 & 1330 & 5661 & $25.78(17.33-35.26)$ & 98.3 & $<0.001$ & & \\
\hline \multirow[t]{3}{*}{ Sample source } & & & & & & & & 554.585 & $<0.001$ \\
\hline & Population-based & 6 & 2769 & 10,426 & $30.58(26.25-35.09)$ & 93.8 & $<0.001$ & & \\
\hline & Community-based & 13 & 6605 & 16,241 & 36.34 (26.93-46.32) & 99.2 & $<0.001$ & & \\
\hline \multirow[t]{3}{*}{ HIV status } & & & & & & & & 11.504 & 0.001 \\
\hline & Positive & 2 & 38 & 149 & $25.75(17.64-34.76)$ & 18.0 & 0.269 & & \\
\hline & Negative & 3 & 344 & 2283 & $16.99(3.17-38.52)$ & 99.1 & $<0.001$ & & \\
\hline
\end{tabular}

It is noteworthy that none of the eligible studies were identified with high quality according to the AHRQ scale. This was specifically because most eligible studies did not indicate how confounding was assessed and did not summarize the completeness of data collection. Furthermore, none of the eligible studies indicated if evaluators of subjective components of study were masked to other aspects of the status of the participants, and explained how missing data were handled in the analysis. A low level of quality of reporting did not necessarily imply a low level of quality of methodology [42]. Additionally, levels of quality of observational studies may differ by different types of assessment scales [43]. Quality is an amorphous concept and it is important to distinguish between the quality of reporting and the quality of methodology, which reflects the susceptibility to bias and assesses the validity [43]. Nonetheless, reporting detailed information on the methods may help identify the appropriateness of methodology. Thus, it is imperative for the researchers to report their findings of observational studies in accordance with the appropriate guidelines, such as the STROBE checklist.

Certain limitations should be acknowledged in this meta-analysis. First, recall bias might exist when collecting information on the lifetime prevalence of suicidal ideation, as a consequence of which, the misclassification of suicidal ideation among the included studies remains a possibility. Second, the heterogeneity in the whole sample and most subgroups was high. The eligible studies included in this meta-analysis came from a varied range of geo-political background with diverse social and environmental factors, which may lead to the high heterogeneity. Additionally, though numerous studies have indicated that psychological stress (i.e. discrimination, stigma and stressful life events) and mental health problems (i.e. depression and anxiety) may affect the lifetime prevalence of suicidal ideation among sexual minorities [44-46], subgroup analyses stratified by these factors were unable to conduct since quite few eligible studies have reported related information among MSM. Future research should, therefore, explore more factors associated with the lifetime prevalence of suicidal ideation among MSM, especially factors related to psychological stress and adverse mental health outcomes. Besides, though some studies have indicated that age may be associated with suicide-related behaviors $[47,48]$, subgroup analysis stratified by age was unable to perform due to the inconsistent cutoff points.

Despite the preceding limitations, this study has quite a few strengths. First, this study provided an update on the pooled lifetime prevalence of suicidal ideation among MSM. Nineteen eligible studies conducted globally were involved, which significantly increased the generalizability of our findings. Second, this metaanalysis provided the first quantitatively pooled lifetime prevalence of suicidal ideation among MSM stratified by the subgroups: geographic area, sample source and HIV status. The different prevalence found within each subgroup would be helpful in identifying the factors associated with suicidal ideation. Finally, low sensitivity and low possibility of publication bias significantly increased the reliability of the findings of this study.

\section{Conclusions}

The pooled lifetime prevalence of suicidal ideation among MSM was 34.97\% (95\% CI: $28.35 \%-41.90 \%)$. For population-based and community-based surveys, the pooled lifetime prevalence was $30.58 \%$ (95\% CI: $26.25 \%-35.09 \%)$ and $36.34 \%$ (95\% CI: 26.93\%$46.32 \%)$, respectively. The lifetime prevalence of 
suicidal ideation among MSM differed significantly by geographic area, sample source and HIV status. The findings of this meta-analysis significantly underscore the importance of early assessment of suicidal ideation among MSM, as well as the need for strengthening the psychological interventions.

\section{Additional files}

Additional file 1: PRISMA Checklist. Description of data: details of PRISMA Checklist. (DOC 64 kb)

Additional file 2: Quality of the eligible studies. Description of data: details about the quality of the eligible studies. (DOCX $17 \mathrm{~kb}$ )

\section{Abbreviations}

AHRQ: Agency for Healthcare Research and Quality; Cl: Confidence interval; LGB: Lesbian, gay and bisexual; MSM: Men who have sex with men; PRISMA: Preferred Reporting Items for Systematic Reviews and Meta-Analyses

\section{Acknowledgments}

The authors are thankful to all authors of the studies included in this meta-analysis.

\section{Funding}

Not applicable.

\section{Availability of data and materials}

Available upon request to the corresponding author Tubao Yang: 1064960669@qq.com.

\section{Authors' contributions}

TY and ZL contributed to the study design. ZL, TF and HF contributed to the data collection. Data analyses and interpretation were performed by $Z \mathrm{~L}$, TF, HF and TY. TY and ZL drafted the manuscript. All authors read and approved the final manuscript.

\section{Ethics approval and consent to participate}

Ethical approval and participant consent were not applicable for this metaanalysis, since this study involved data and materials from published articles.

\section{Consent for publication}

Not applicable.

\section{Competing interests}

The authors declare that they have no competing interests.

\section{Publisher's Note}

Springer Nature remains neutral with regard to jurisdictional claims in published maps and institutional affiliations.

\section{Author details}

${ }^{1}$ Department of Epidemiology and Health Statistics, Xiangya School of Public Health, Central South University, Hunan, China. ${ }^{2}$ Shenzhen Nanshan Center for Chronic Disease Control, Guangdong, China. ${ }^{3}$ Shenzhen Center for Chronic Disease Control, Guangdong, China.

\section{Received: 14 April 2017 Accepted: 11 December 2017}

Published online: 21 December 2017

\section{References}

1. Hottes TS, Ferlatte O, Gesink D. Suicide and HIV as leading causes of death among gay and bisexual men: a comparison of estimated mortality and published research. Critical Public Health. 2015;25(5):513-26. doi:10.1080/ 09581596.2014.946887

2. Wang Y, Zhang HB, Xu J, Zhang GG, Yang HW, Fan J. Relationship between suicidal behaviors of MSM and social-psychological factors. Pract Prev Med. 2011;18(2):232-5.
3. Zhang BC, Li NF, Chu QS, Wang N, Wang ZG, Zhou SG, et al. Correlation between AIDS and homosexuals: a study of 2046 male homosexuals in nine major cities in China. Chin J Hum Sex. 2008;17(8):6-10.

4. Zheng W, Wang M, Wu ZX, Zhang BC, Pi Q. Analysis on influencing factors of suicide behavior among MSM in Wuhan. J Public Health Prev Med. 2012;3(1):51-5.

5. Centers for Disease Control and Prevention. Definitions: self-directed violence. Atlanta: CDC; 2014

6. Klonsky ED, May AM, Saffer BY. Suicide, suicide attempts, and suicidal ideation. Annu Rev Clin Psychol. 2016;12:307-30. doi:10.1146/annurevclinpsy-021815-093204.

7. Hubers AA, Moaddine S, Peersmann SH, Stijnen T, van Duijn E, van der Mast $\mathrm{RC}$, et al. Suicidal ideation and subsequent completed suicide in both psychiatric and non-psychiatric populations: a meta-analysis. Epidemiol Psychiatr Sci. 2016:1-13. doi:10.1017/s2045796016001049.

8. de Graaf R, Sandfort TG, ten Have M. Suicidality and sexual orientation: differences between men and women in a general population-based sample from the Netherlands. Arch Sex Behav. 2006;35(3):253-62. doi:10. 1007/s10508-006-9020-z

9. Glick S, Kerani R, Golden M. Mortality among men who have sex with men seen in STD clinic patients: high rates of suicide and low rates of anal cancer death. Sex Transm Infect. 2011;87:A156-A. doi:10.1136/sextrans-2011-050108.136.

10. Stahlman S, Grosso A, Ketende S, Pitche V, Kouanda S, Ceesay N, et al. Suicidal ideation among MSM in three West African countries: associations with stigma and social capital. Int J Soc Psychiatry. 2016;62(6):522-31. doi:10. 1177/0020764016663969.

11. Ferlatte O, Salway T, Oliffe JL, Trussler T. Stigma and suicide among gay and bisexual men living with HIV. AIDS Care. 2017;29(11):1346-50. doi:10.1080/ 09540121.2017.1290762.

12. Mathy RM. Suicidality and sexual orientation in five continents: Asia, Australia, Europe, North America, and South America. Int J Sex Gend Stud. 2002:7(2-3):215-25.

13. Yi S, Tuot S, Chhoun P, Pal K, Choub SC, Mburu G. Mental health among men who have sex with men in Cambodia: implications for integration of mental health services within HIV programmes. Int J Equity Health. 2016;15: 53. doi:10.1186/s12939-016-0342-8.

14. Wang J, Hausermann M, Wydler H, Mohler-Kuo M, Weiss MG. Suicidality and sexual orientation among men in Switzerland: findings from 3 probability surveys. J Psychiatr Res. 2012;46(8):980-6. doi:10.1016/j.jpsychires.2012.04.014.

15. King M, Semlyen J, Tai SS, Killaspy H, Osborn D, Popelyuk D, et al. A systematic review of mental disorder, suicide, and deliberate self harm in lesbian, gay and bisexual people. BMC Psychiatry. 2008:8:70. doi:10.1186/ $1471-244 x-8-70$

16. Hottes TS, Bogaert L, Rhodes AE, Brennan DJ, Gesink D. Lifetime prevalence of suicide attempts among sexual minority adults by study sampling strategies: a systematic review and meta-analysis. Am J Public Health. 2016; 106(5):e1-12. doi:10.2105/ajph.2016.303088.

17. Chow EP, Wilson DP, Zhang L. HIV and syphilis co-infection increasing among men who have sex with men in China: a systematic review and meta-analysis. PLoS One. 2011;6(8):e22768. doi:10.1371/journal.pone. 0022768.

18. Wu J, Hu Y, Jia Y, Su Y, Cui H, Liu H, et al. Prevalence of unprotected anal intercourse among men who have sex with men in China: an updated meta-analysis. PLoS One. 2014;9(5):e98366. doi:10.1371/journal. pone.0098366.

19. Smoak ND, Scott-Sheldon LA, Johnson BT, Carey MP. Sexual risk reduction interventions do not inadvertently increase the overall frequency of sexual behavior: a meta-analysis of 174 studies with 116,735 participants. J Acquir Immune Defic Syndr. 2006;41(3):374-84. doi:10.1097/01.qai.0000185575. 36591.fc.

20. Marshal MP, Dietz LJ, Friedman MS, Stall R, Smith HA, McGinley J, et al. Suicidality and depression disparities between sexual minority and heterosexual youth: a meta-analytic review. J Adolesc Health. 2011;49(2): $115-23$.

21. Ploderl M, Tremblay P. Mental health of sexual minorities. A systematic review. Int Rev Psychiatry. 2015;27(5):367-85. doi:10.3109/09540261.2015. 1083949.

22. Herbst JH, Sherba RT, Crepaz N, Deluca JB, Zohrabyan L, Stall RD, et al. A meta-analytic review of HIV behavioral interventions for reducing sexual risk behavior of men who have sex with men. J Acquir Immune Defic Syndr. 2005;39(2):228-41. 
23. Rooney BM, Tulloch TG, Blashill AJ. Psychosocial syndemic correlates of sexual compulsivity among men who have sex with men: a meta-analysis. Arch Sex Behav. 2017; doi:10.1007/s10508-017-1032-3.

24. Vu NT, Maher L, Zablotska I. Amphetamine-type stimulants and HIV infection among men who have sex with men: implications on HIV research and prevention from a systematic review and meta-analysis. J Int AIDS Soc. 2015;18:19273. doi:10.7448/ias.18.1.19273.

25. Yang LS, Zhang ZH, Sun L, Sun YH, Ye DQ. Prevalence of suicide attempts among college students in China: a meta-analysis. PLoS One. 2015;10(2): e0116303. doi:10.1371/journal.pone.0116303.

26. Hu J, Dong Y, Chen X, Liu Y, Ma D, Liu X, et al. Prevalence of suicide attempts among Chinese adolescents: a meta-analysis of cross-sectional studies. Compr Psychiatry. 2015;61:78-89. doi:10.1016/j.comppsych.2015.05.001.

27. Li Y, Li Y, Cao J. Factors associated with suicidal behaviors in mainland China: a meta-analysis. BMC Public Health. 2012;12:524. doi:10.1186/1471-2458-12-524.

28. Han C, Zhang M, Luo X, Wang C, Yin L, Pang C, et al. Secular trends in the prevalence of type 2 diabetes in adults in China from 1995 to 2014: a metaanalysis. J Diabetes. 2017;9(5):450-61. doi:10.1111/1753-0407.12440.

29. Dai W, Chen L, Lai Z, Li Y, Wang J, Liu A. The incidence of post-traumatic stress disorder among survivors after earthquakes:a systematic review and meta-analysis. BMC Psychiatry. 2016;16:188. doi:10.1186/s12888-016-0891-9.

30. Chen X, Li L, Zhou T, Li Z. Prevalence of hypertension in rural areas of china: a meta-analysis of published studies. PLoS One. 2014;9(12):e115462. doi:10. 1371/journal.pone.0115462.

31. Begg CB, Mazumdar M. Operating characteristics of a rank correlation test for publication bias. Biometrics. 1994;50(4):1088-101.

32. He Q, Peng WJ, Zhang JQ, Wang BX, Wang J. Prevalence of unprotected anal intercourse and unprotected vaginal intercourse among HIV-positive men who have sex with men in China: a meta-analysis. Sex Transm Infect. 2012;88(3):229-33. doi:10.1136/sextrans-2011-050230.

33. Gao L, Zhang L, Jin Q. Meta-analysis: prevalence of HIV infection and syphilis among MSM in China. Sex Transm Infect. 2009;85(5):354-8. doi:10. 1136/sti.2008.034702

34. Wang J, Hausermann M, Berrut S, Weiss MG. The impact of a depression awareness campaign on mental health literacy and mental morbidity among gay men. J Affect Disord. 2013;150(2):306-12. doi:10.1016/j.jad.2013.04.011.

35. Rotenstein LS, Ramos MA, Torre M, Segal JB, Peluso MJ, Guille C, et al. Prevalence of depression, depressive symptoms, and suicidal ideation among medical students: a systematic review and meta-analysis. JAMA. 2016;316(21):2214-36. doi:10.1001/jama.2016.17324

36. Dong Y, Huang F, Hu G, Liu Y, Zheng R, Zhang Q, et al. The prevalence of suicidal ideation among the elderly in China: a meta-analysis of 11 crosssectional studies. Compr Psychiatry. 2014;55(5):1100-5. doi:10.1016/j. comppsych.2014.02.010.

37. Li ZZ, Li YM, Lei XY, Zhang D, Liu L, Tang SY, et al. Prevalence of suicidal ideation in Chinese college students: a meta-analysis. PLoS One. 2014;9(10): e104368. doi:10.1371/journal.pone.0104368.

38. Cao XL, Zhong BL, Xiang YT, Ungvari GS, Lai KY, Chiu HF, et al. Prevalence of suicidal ideation and suicide attempts in the general population of China: a meta-analysis. Int J Psychiatry Med. 2015;49(4):296-308. doi:10.1177/ 0091217415589306.

39. Steele LS, Ross LE, Dobinson C, Veldhuizen S, Tinmouth JM. Women's sexual orientation and health: results from a Canadian population-based survey. Women Health. 2009;49(5):353-67. doi:10.1080/03630240903238685.

40. Gustafson P, Gilbert M, Xia M, Michelow W, Robert W, Trussler T, et al. Impact of statistical adjustment for frequency of venue attendance in a venue-based survey of men who have sex with men. Am J Epidemiol. 2013; 177(10):1157-64. doi:10.1093/aje/kws358.

41. Siegel $\mathrm{K}$, Meyer $\mathrm{H}$. Hope and resilience in suicide ideation and behavior of gay and bisexual men following notification of HIV infection. AIDS Educ Prev. 1999;11(1):53-64.

42. Huwiler-Muntener K, Juni P, Junker C, Egger M. Quality of reporting of randomized trials as a measure of methodologic quality. JAMA. 2002; 287(21):2801-4.

43. Sanderson S, Tatt ID, Higgins JP. Tools for assessing quality and susceptibility to bias in observational studies in epidemiology: a systematic review and annotated bibliography. Int J Epidemiol. 2007;36(3):666-76. doi: 10.1093/ije/dym018.

44. Ploderl M, Fartacek R. Suicidality and associated risk factors among lesbian, gay, and bisexual compared to heterosexual Austrian adults. Suicide Life Threat Behav. 2005;35(6):661-70.
45. Flynn AB, Johnson RM, Bolton SL, Mojtabai R. Victimization of lesbian, gay, and bisexual people in childhood: associations with attempted suicide. Suicide Life Threat Behav. 2016;46(4):457-70. doi:10.1111/sltb.12228.

46. Meyer $\mathbb{H}$. Prejudice, social stress, and mental health in lesbian, gay, and bisexual populations: conceptual issues and research evidence. Psychol Bull. 2003;129(5):674-97. doi:10.1037/0033-2909.129.5.674.

47. Mu H, Li Y, Liu L, Na J, Yu L, Bi X, et al. Prevalence and risk factors for lifetime suicide ideation, plan and attempt in Chinese men who have sex with men. BMC Psychiatry. 2016;16:117. doi:10.1186/s12888-016-0830-9.

48. Safer DJ. Adolescent/adult differences in suicidal behavior and outcome. Ann Clin Psychiatry. 1997;9(1):61-6.

49. Cochran SD, Mays VM. Lifetime prevalence of suicide symptoms and affective disorders among men reporting same-sex sexual partners: results from NHANES III. Am J Public Health. 2000;90(4):573-8.

50. Botnick MR, Heath KV, Cornelisse PG, Strathdee SA, Martindale SL, Hogg RS. Correlates of suicide attempts in an open cohort of young men who have sex with men. Can J Public Health. 2002;93(1):59-62.

51. Warner J, McKeown E, Griffin M, Johnson K, Ramsay A, Cort C, et al. Rates and predictors of mental illness in gay men, lesbians and bisexual men and women: results from a survey based in England and Wales. Br J Psychiatry. 2004;185:479-85. doi:10.1192/bjp.185.6.479.

52. Sheridan S, Phimphachanh C, Chanlivong N, Manivong S, Khamsyvolsvong S, Lattanavong $\mathrm{P}$, et al. HIV prevalence and risk behaviour among men who have sex with men in Vientiane Capital, Lao People's Democratic Republic 2007. AIDS. 2009;23(3):409-14. doi:10.1097/QAD.0b013e32831ef510.

53. Brennan DJ, Ross LE, Dobinson C, Veldhuizen S, Steele LS. Men's sexual orientation and health in Canada. Can J Public Health. 2010;101(3):255-8.

54. Deuba K, Ekstrom AM, Shrestha R, lonita G, Bhatta L, Karki DK. Psychosocial health problems associated with increased HIV risk behavior among men who have sex with men in Nepal: a cross-sectional survey. PLoS One. 2013; 8(3):e58099. doi:10.1371/journal.pone.0058099.

55. Chen H, Li Y, Wang L, Zhang B. Causes of suicidal behaviors in men who have sex with men in China: a national questionnaire survey. BMC Public Health. 2015;15:91. doi:10.1186/s12889-015-1436-8.

56. Ferlatte O, Dulai J, Hottes TS, Trussler T, Marchand R. Suicide related ideation and behavior among Canadian gay and bisexual men: a syndemic analysis. BMC Public Health. 2015;15:597. doi:10.1186/s12889-015-1961-5.

57. Parker RD, Lohmus L, Valk A, Mangine C, Ruutel K. Outcomes associated with anxiety and depression among men who have sex with men in Estonia. J Affect Disord. 2015;183:205-9. doi:10.1016/j.jad.2015.05.014.

58. Blosnich JR, Nasuti L, Mays VM, Cochran SD. Suicidality and sexual orientation: characteristics of symptom severity, disclosure, and timing across the life course. Am J Orthop. 2016;86(1):69-78. doi:10.1037/ort0000112.

59. Hottes TS, Gesink D, Ferlatte O, Brennan DJ, Rhodes AE, Marchand R, et al. Concealment of sexual minority identities in interviewer-administered government surveys and its impact on estimates of suicide ideation among bisexual and gay men. J Bisexuality. 2016;16(4):427-53. doi:10.1080/ 15299716.2016 .1225622

60. Hladik W, Sande E, Berry M, Ganafa S, Kiyingi H, Kusiima J, et al. Men who have sex with men in Kampala, Uganda: results from a bio-behavioral respondent driven sampling survey. AIDS Behav. 2016; doi:10.1007/s10461016-1535-2.

61. Kohlbrenner V, Deuba K, Karki DK, Marrone G. Perceived discrimination is an independent risk factor for suicidal ideation among sexual and gender minorities in Nepal. PLoS One. 2016;11(7):e0159359. doi:10.1371/journal. pone.0159359. 